\title{
Variability of the Critical Frequency foF2 during Minimum and Maximum Phases of Solar Cycles 20 and 21: A Comparative Study between American and African Equatorial Regions
}

\author{
Kaboré $\mathbf{M}^{\prime} \mathbf{B i}^{1,2^{*}}$, Diabaté Abidina ${ }^{2}$, Ouattara Frédéric ${ }^{1}$ \\ ${ }^{1}$ Laboratoire de Recherche en Energétique et Météorologie de l'Espace (LAREME) Université Norbert Zongo, \\ Koudougou, Burkina Faso \\ ${ }^{2}$ Laboratoire de Matériaux, d'Héliophysique et Environnement (LAMHE), Université Nazi Boni, \\ Bobo Dioulasso, Burkina Faso \\ Email: *mb_kabore@yahoo.fr
}

How to cite this paper: M'Bi, K., Abidina, D. and Frédéric, O. (2022) Variability of the Critical Frequency foF2 during Minimum and Maximum Phases of Solar Cycles 20 and 21: A Comparative Study between American and African Equatorial Regions. Atmospheric and Climate Sciences, 12, 105-112.

https://doi.org/10.4236/acs.2022.121008

Received: November 10, 2021

Accepted: January 2, 2021

Published: January 5, 2021

Copyright $\odot 2022$ by author(s) and Scientific Research Publishing Inc. This work is licensed under the Creative Commons Attribution International License (CC BY 4.0).

http://creativecommons.org/licenses/by/4.0/

\section{(c) (i) Open Access}

\begin{abstract}
The present work is a comparative study between the foF 2 variabilities for two equatorial regions (Ouagadougou: lat. $12^{\circ} 21^{\prime} \mathrm{N}$; long. $1^{\circ} 30^{\prime} \mathrm{E}$, dip. $1.43^{\circ}$ in Africa and Huancayo: Lat. $12^{\circ} \mathrm{S}$; Long. $75^{\circ} 12^{\prime} \mathrm{W}$ in America) during solar cycles 20 and 21 minima and maxima phases under geomagnetic extreme conditions (quiet and disturb). Profiles from these two stations are very similar for all the seasons over the solar cycles. However, measured data from Huancayo station are higher than those from Ouagadougou station during winter with a reverse phenomenon for summer. The investigations suggest that the gap between foF 2 values and the reverse phenomenon observed for the two stations may be explained by their hemispheric location (Huancayo in south hemisphere and Ouagadougou in North one). Longitudinal irregularities in ionosphere may also contribute to that little difference observed during the time interval of our investigation.
\end{abstract}

\section{Keywords}

foF2, Longitudinal Variation, Seasonal Variation

\section{Introduction}

The ionosphere is an ionized layer of Earth's atmosphere. It is one of the most important layers of Earth's atmosphere for its role in wave propagations (communication). Understanding the behavior of this region may be useful for inves- 
tigations of solar disturbances and their terrestrial impacts. To better seize the level of the variations of this region in the equatorial region through its critical frequency foF2 profiles many authors have reviewed the seasonal variations of foF2 [1]-[14]. This ionospheric parameter through its in situ measurements allowed [6] to classify foF2 diurnal profiles as follow: 1) Morning peak profile characterized by a predominance morning peak; 2) Plateau profile; 3) Dome profile; 4) Reverse profile characterized by predominance afternoon peak; 5) noon bite out profile due to the presence of double peaks (morning and afternoon peaks) with trough around midday. All these previous investigations have provided useful suggestions for the prediction in the GNSS recordings.

The objectives of our present investigation are to better understand the dynamic of the ionosphere in two regions (Ouagadougou: lat. $12^{\circ} 21^{\prime} \mathrm{N}$; long. $1^{\circ} 30^{\prime} \mathrm{E}$, dip. $1.43^{\circ}$ in Africa and Huancayo: Lat. $12^{\circ} \mathrm{S}$; Long. $75^{\circ} 12^{\prime} \mathrm{W}$ in America).

In the current study, foF 2 data from Ouagadougou and Huancayo ionosonde stations are used to illustrate the various characteristics of the F2 layer of the ionosphere through is critical frequency foF2 seasonal time variation during solar cycle minima and maxima for Ouagadougou and Huancayo.

\section{Data and Methodology}

\subsection{Data}

1) The ionospheric parameter studied is the critical frequency of the F2 layer (foF2) taken from www.spidr.ngdc.noaa.gov. 2) The values of sunspots $\mathrm{Rz}$ are obtained from the SPIDR database (URL http://sidc.oma.be/sunspot-data/. 3) The geomagnetic index aa used to selected quiet days conditions are from http://isgi.unistra.fr/data_download.php. Figure 1 is an example of pixel diagram displaying aa index as a table and allowing us to select geomagnetic conditions [15] [16].

\subsection{Methodology}

The Solar cycle phases are determined using sunspot number $\mathrm{Rz}$ [17] and criteria fully described in many works [18] [19]: 1) the minimum phase: $\mathrm{Rz}<20 ; 2$ ) the ascending phase: $20 \leq \mathrm{Rz} \leq 100$ and $\mathrm{Rz}$ greater than the previous year's value; 3) the maximum phase: $\mathrm{Rz}>100$; 4) the decreasing phase: $100 \geq \mathrm{Rz} \geq 20$ and $\mathrm{Rz}$ less than the previous year values.

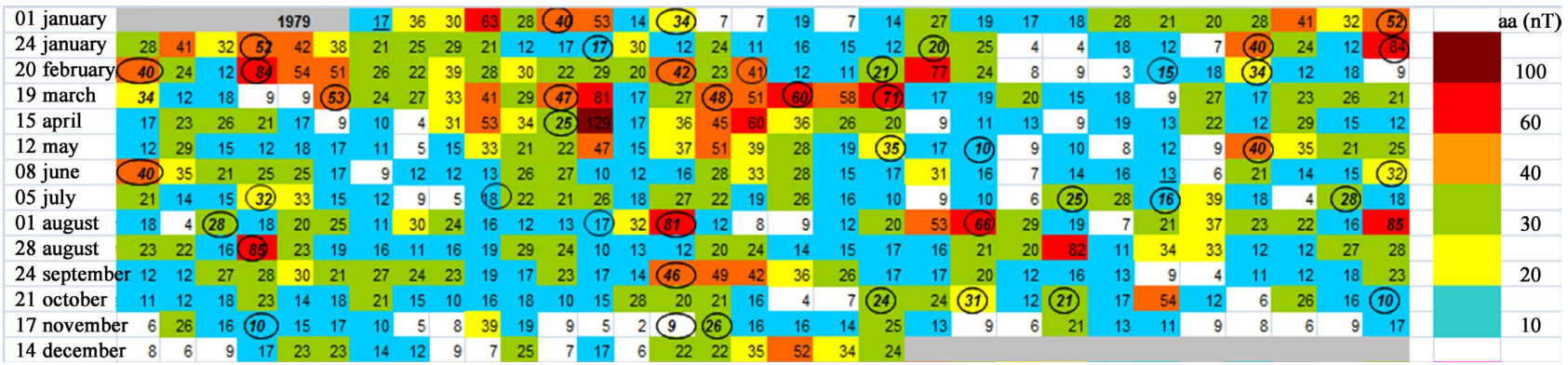

Figure 1. Diagram pixel of year 1979. 
Local (north hemispheric) seasons are classified as followed: winter (December, January, and February); spring (March, April, May); summer (June, July, August) and autumn (September, October and November).

To perform our study, we proceed as follow:

1) At solar maximum and solar minimum: select days with the highest $\mathrm{Rz}$ and the lowest $\mathrm{Rz}$ respectively;

2) Choose five days the most disturbed (highest aa index) and five quietest (aa lowest index);

3) Monthly and seasonal average (hourly) of foF2 per cycle and solar activity.

\section{Results and Discussion}

In this section we present and analyze the results of our investigations in other to allow comparison between measurements from two equatorial regions: Africa and America.

Figures 2-5 present the diurnal variation of foF2 during geomagnetic quiet

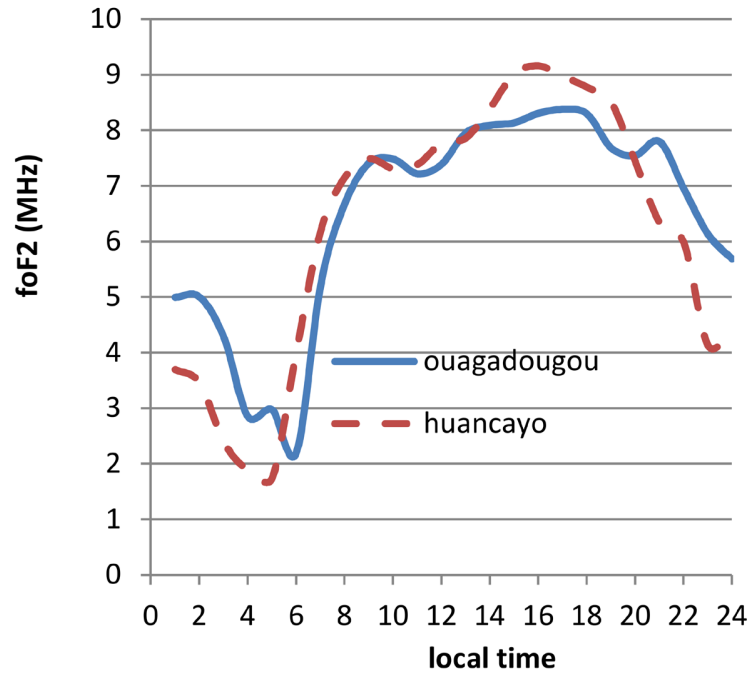

(a)

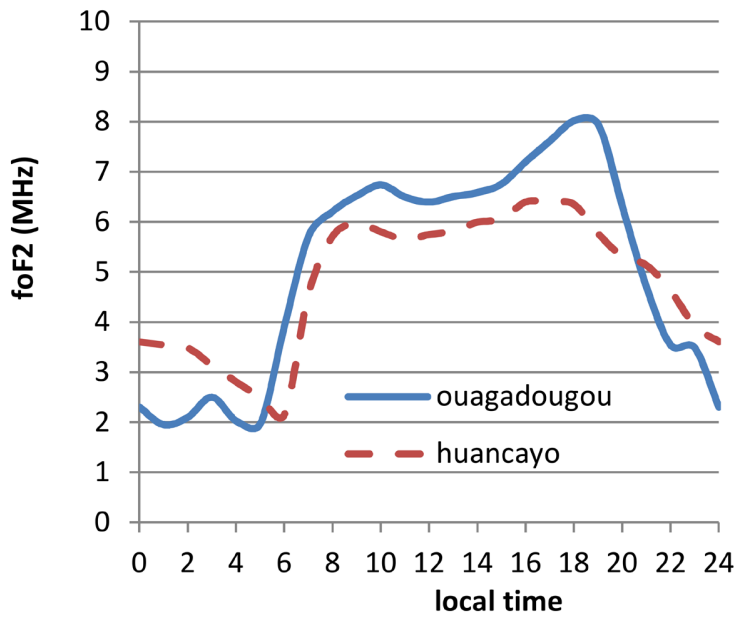

(c)

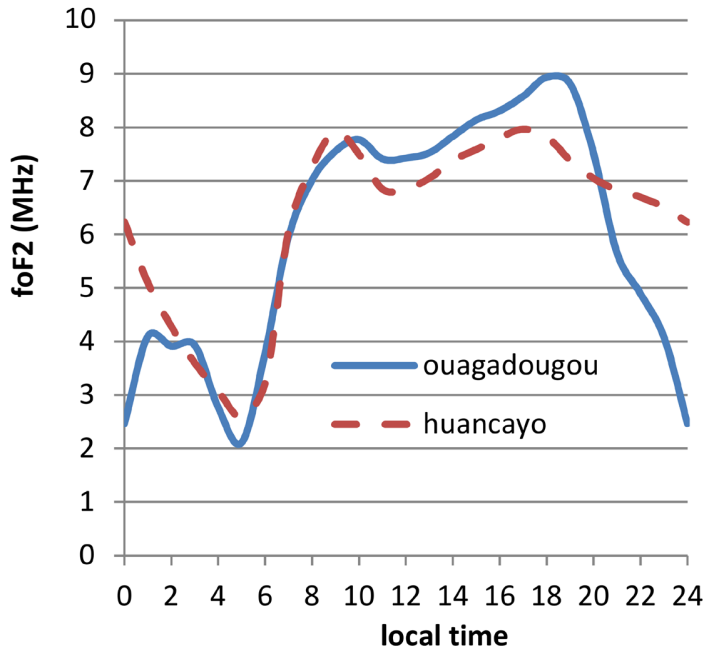

(b)

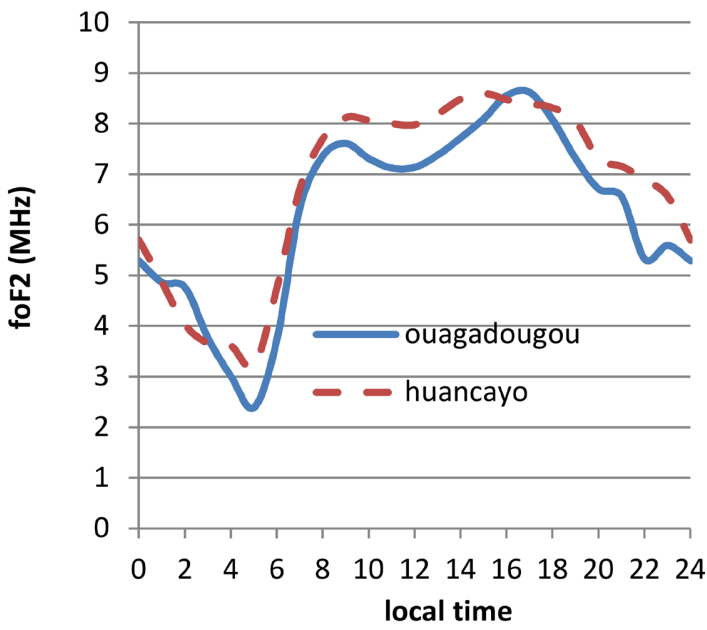

(d)

Figure 2. Diurnal and seasonal foF2 during solar minimum phase of the cycle solar 20. 


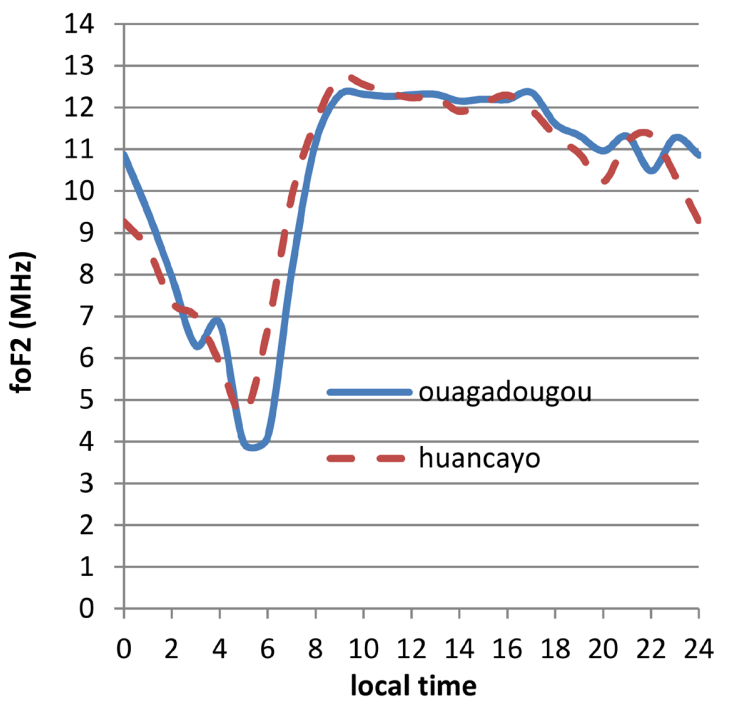

(a)

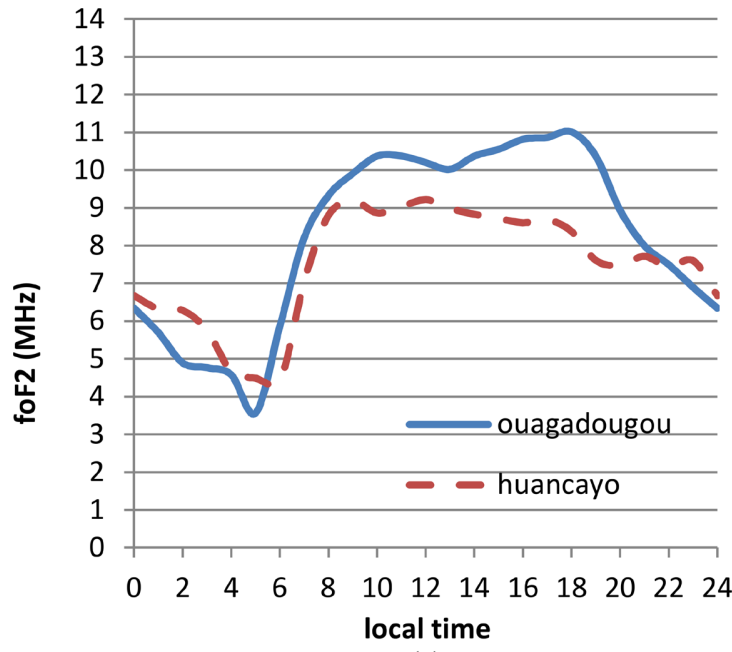

(c)

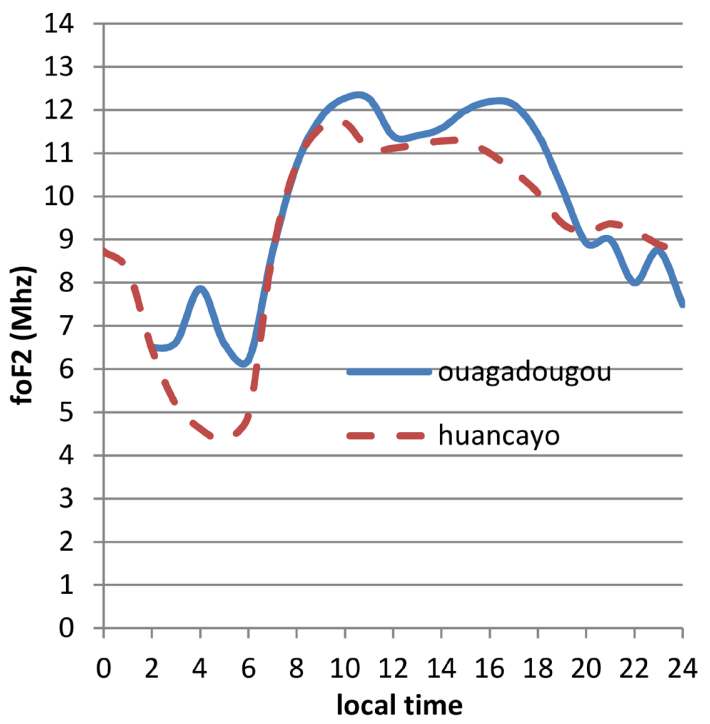

(b)

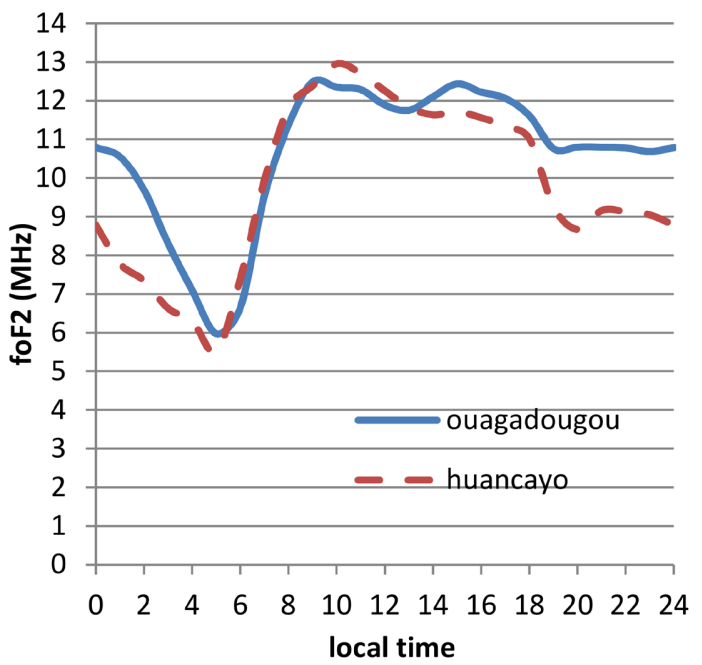

(d)

Figure 3. Diurnal and seasonal foF2 during solar maximum phase of the cycle solar 20.

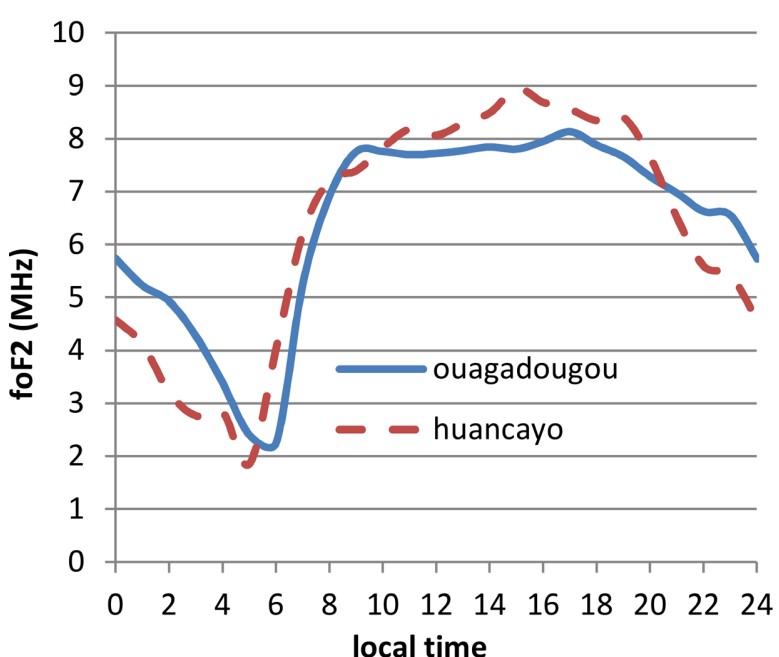

(a)

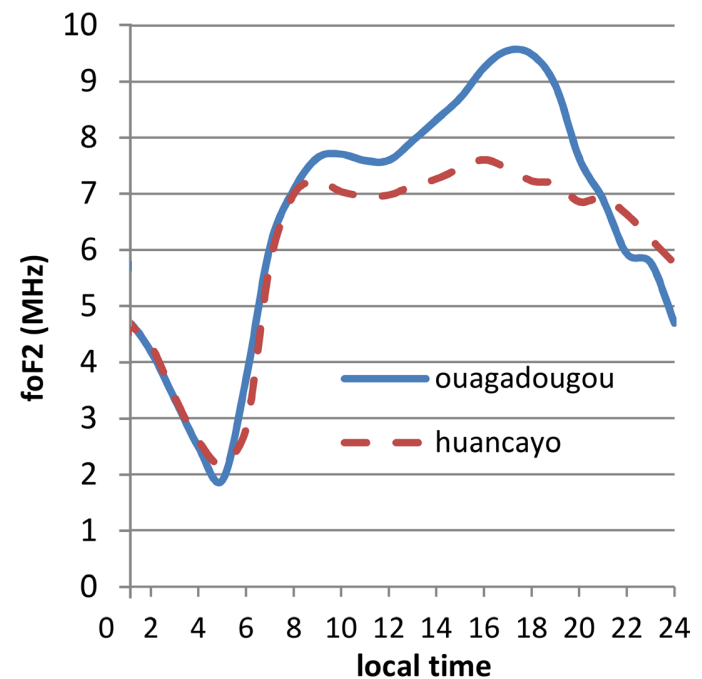

(b) 


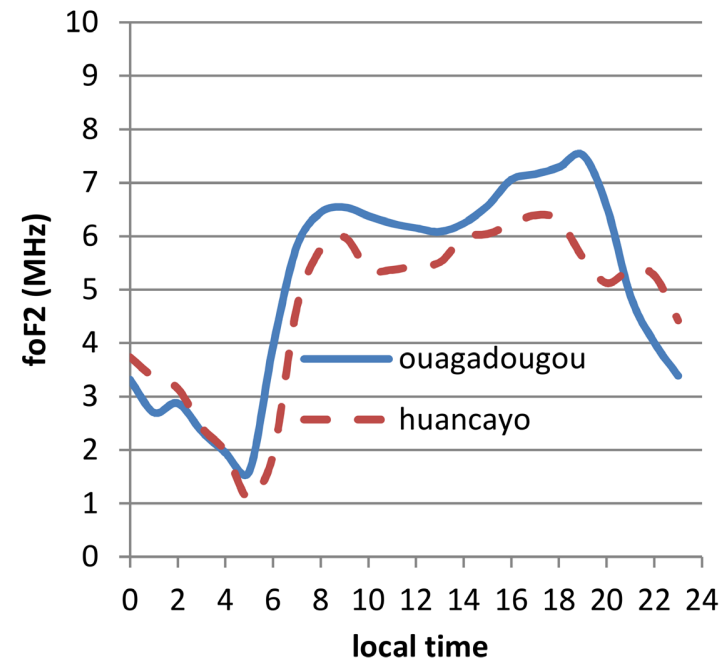

(c)

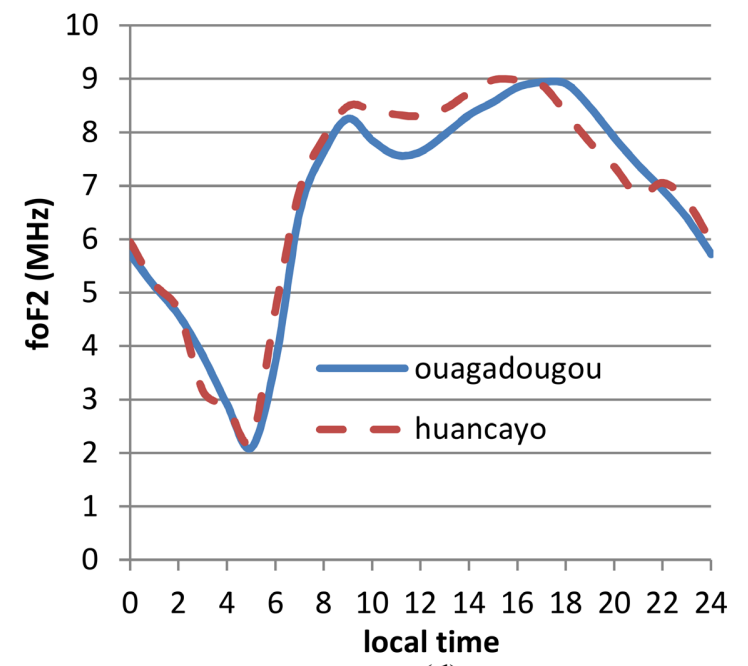

(d)

Figure 4. Diurnal and seasonal foF2 during solar minimum phase of the cycle solar 21.

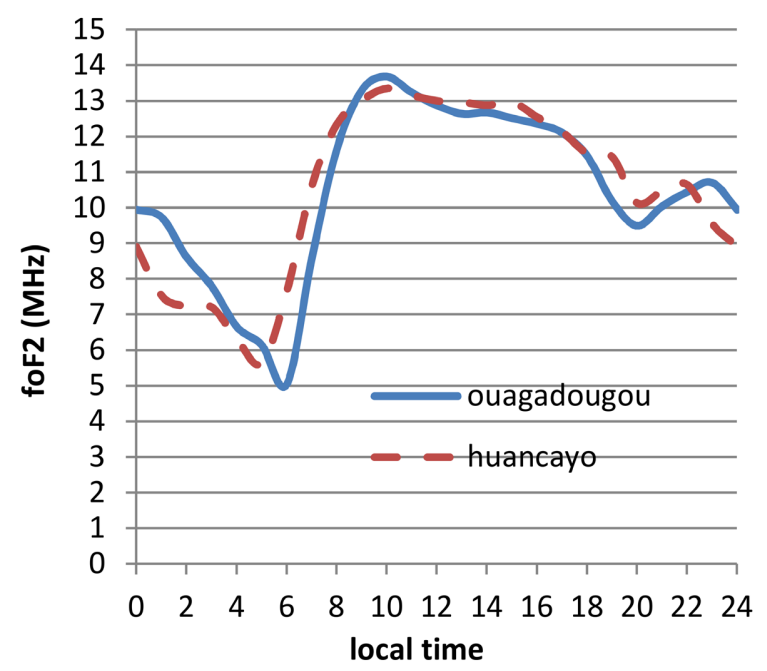

(a)

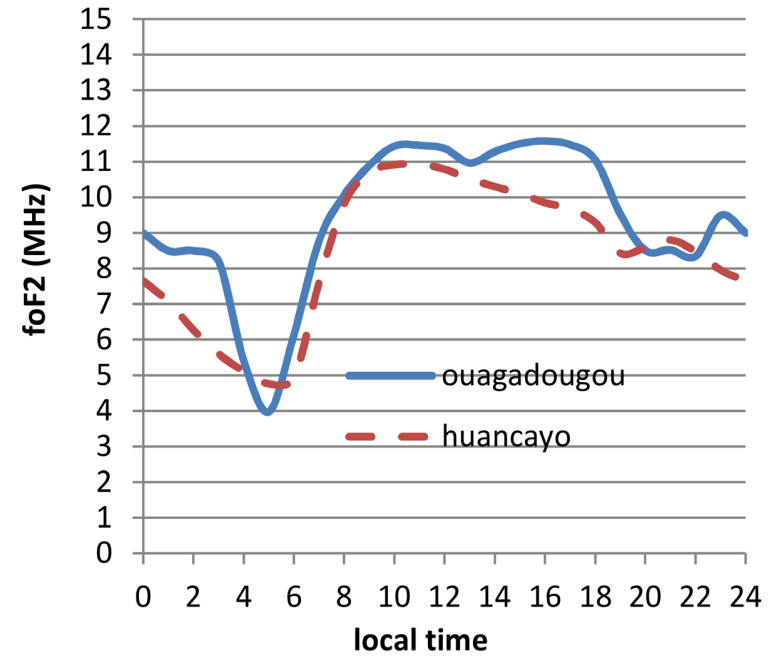

(c)

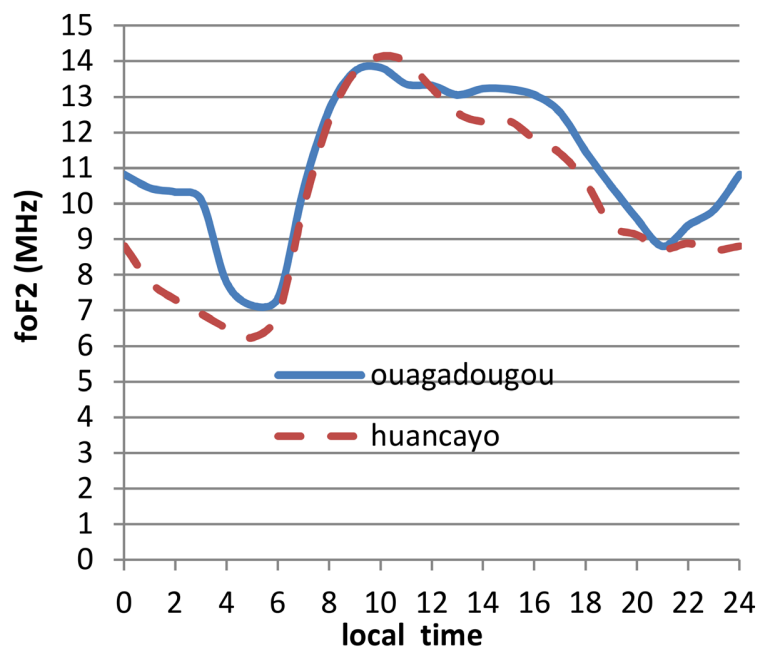

(b)

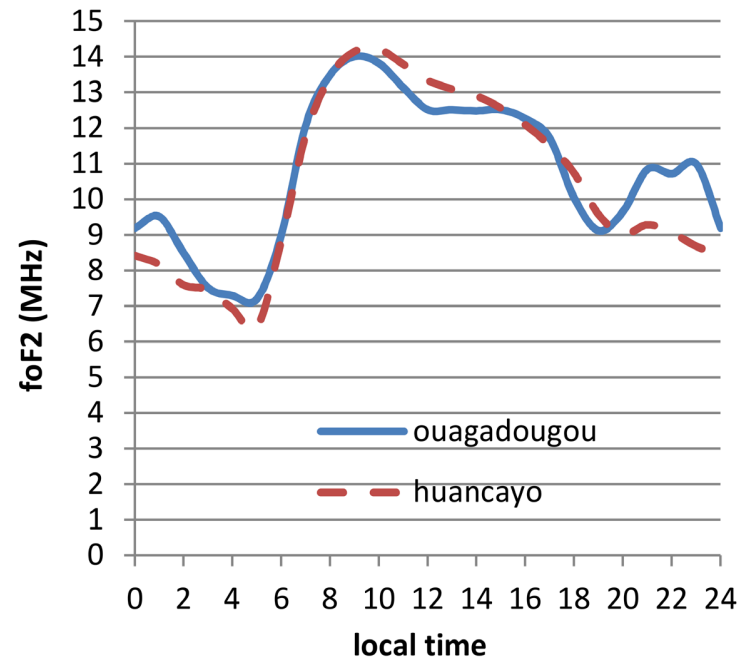

(d)

Figure 5. Diurnal and seasonal foF2 during solar maximum phase of the cycle solar 21. 
activity for solar minima and disturbed geomagnetic activity for solar maxima at Ouagadougou and Huancayo stations over the solar cycle 20 (1965-1976) and the solar cycle 21 (1976-1986) Each figure show the seasonal (a-Winter, $\mathrm{b}$-Spring, c-Summer, d-Autumn) behavior of foF2 during our investigation period. It is easy to remark that all the profiles suggested by [12] for equatorial region in Africa are reproduced at Huancayo station. During the minimum phase of the solar cycle 21 foF 2 presents "Dome" or " $D$ " profile characterized by a double peak (morning and evening) in winter while "Noon bite out" or "B" profile characterized morning is recorded for the three other seasons (Figure 4). Regardless of the season, foF2 presents "Morning Peak" or " $M$ " profile during the solar maximum phases for both solar cycles 20 and 21 (Figure 3 and Figure 5 ). During the minimum phase of solar cycle 20, foF 2 presents "Noon bite out" or " $\mathrm{B}$ " profile for all the seasons except winter where foF2 is characterized by "Reversed" or "R" profile.

From these investigations it appears for both solar cycles 20 and 21, foF2 presents similar profiles for the two stations. The little difference in magnitude may be attributed to the longitudinal irregularities in the F2-layer [20]. Table 1 summaries the most important seasonal values of foF2 during solar cycle and solar activity for Ouagadougou and Huancayo stations.

In general, the recorded values of foF 2 at Huancayo station are higher than those from Ouagadougou station during winter. A reverse phenomenon is observed during summer. These observations for two equatorial regions may be due to the fact that they are not located in the same hemisphere (seasons are permitted).

\section{Conclusion}

Seasonal and diurnal profiles of foF2 values measured at the stations of Huancayo and Ouagadougou present a similar morphology with little difference during winter and summer. The difference observed during these seasons can be

Table 1. Comparative value of most significant values of foF2 during season and solar cycle phases Ouagadougou and Huancayo stations.

\begin{tabular}{cccccc}
\hline Stations & Solar Cycle phases & $\begin{array}{c}\text { Winter } \\
\text { foF2 }(\mathrm{Mhz})\end{array}$ & $\begin{array}{c}\text { Spring } \\
\text { foF2 }(\mathrm{Mhz})\end{array}$ & $\begin{array}{c}\text { Summer } \\
\text { foF2 (Mhz) }\end{array}$ & $\begin{array}{c}\text { Autunm } \\
\text { foF2 (Mhz) }\end{array}$ \\
\hline \multirow{3}{*}{ Ouagadougou } & Minimum of Cycle 20 & 08.30 & 08.82 & 07.95 & 08.62 \\
& Maximum of Cycle 20 & 12.36 & 12.27 & 11.01 & 12.49 \\
& Minimum of Cycle 21 & 08.13 & 09.56 & 07.52 & 08.91 \\
& Maximum of Cycle 21 & 13.68 & 13.73 & 11.60 & 14.21 \\
& Minimum of Cycle 20 & 09.02 & 07.56 & 06.35 & 08.60 \\
& Maximum of Cycle 20 & 12.55 & 11.83 & 09.91 & 12.71 \\
& Minimum of Cycle 21 & 08.94 & 07.61 & 06.39 & 08.98 \\
& Maximum of Cycle 21 & 13.35 & 14.13 & 10.13 & 14.15 \\
\hline
\end{tabular}


explained by the fact that the two stations are located in different hemispheres. The season may be reversed in the hemispheres strongly link to the ionization phenomenon. Solstice anomaly is observed only during the intense geomagnetic activity (solar maximum) as summarized in table for these two stations.

\section{Acknowledgements}

The authors thank Brest Telecom for providing Ouagadougou ionosonde data and ISGI and SPIDR data center for providing the aa indices and foF2 respectively.

Many thanks are sent to ACS editors and anonymous reviewers of our paper.

\section{Conflicts of Interest}

The authors declare no conflicts of interest regarding the publication of this paper.

\section{References}

[1] Ouattara, F. and Zerbo, J.L. (2011) Ouagadougou Station F2 Layer Parameters, Yearly and Seasonal Variations during Severe Geomagnetic Storms Generated by Coronal Mass Ejections (CMEs) and Fluctuating Wind Streams. International Journal of the Physical Sciences, 6, 4854-4860.

[2] Adeniyi, J.O. and Adimula, I.A. (1995) Comparing the F2-Layer Model of IRI with Observations at Ibadan. Advanced in Space Research, 15, 141-144.

https://doi.org/10.1016/S0273-1177(99)80036-2

[3] Abdu, M.A., Batista, I.S. and De Souza, J.R. (1996) An Overview of IRI-Observational Data Comparison in American (Brazilian) Sector Low Latitude Ionosphere. Advanced in Space Research, 18, 13-22. https://doi.org/10.1016/0273-1177(95)00893-4

[4] Batista, S., Abdu, M.A., De Medeiros, R.T. and De Paula, E.R. (1996) Comparison between IRI Predictions and Digisonde Measurements at Low Latitude Station. Advanced in Space Research, 18, 49-52. https://doi.org/10.1016/0273-1177(95)00899-3

[5] Bertoni, F., Sahai, Y., Lima, L., Fagundes, P., Pillat, V., Becker-Guedes, F. and Abalde, J. (2006) IRI-2001 Model Predictions Compared with Ionospheric Data Observed at Brazilian Low Latitude Stations. Annales Geophysicae, 24, 2191-2200. https://doi.org/10.5194/angeo-24-2191-2006

[6] Bilitza, D., Altadill, D., Zhang, Y., Mertens, C., Truhlik, V., Richards, P., McKinnell, L.A. and Reinisch, B. (2014) The International Reference Ionosphere 2012-A Model of International Collaboration. Journal of Space Weather and Space Climate $A, 7,1-12$. https://doi.org/10.1051/swsc/2014004

[7] Ouattara, F. and Fleury, R. (2011) Variability of CODG TEC and IRI 2001 Total Electron Content (TEC) during IHY Campaign Period (21 March to 16 April 2008) at Niamey under Different Geomagnetic Activity Conditions. Scientific Research and Essays, 17, 3609-3622. http://www.academicjournals.org/SRE https://doi.org/10.5897/SRE

[8] Tariku, Y.A. (2015) TEC Prediction Performance of the IRI-2012 Model over Ethiopia during the Rising Phase of Solar Cycle 24 (2009-2011). Earth, Planets and Space, 67, 140. https://doi.org/10.1186/s40623-015-0312-1

[9] Li, S., Li, L. and Peng, J. (2016) Variability of Ionospheric TEC and the Performance 
of the IRI-2012 Model at the BJFS Station, China. Acta Geophysica, 64, 1970-1987. https://doi.org/10.1515/acgeo-2016-0075

[10] Sawadogo, W.E., Zerbo, J.-L. and Ouattara, F. (2019) Diurnal Variation of F2-Layer Critical Frequency under Solar Activity Recurrent Conditions during Solar Cycles 21 and 22 at Ouagadougou Station: Prediction with IRI-2012. Scientific Research and Essays, 14, 111-118.

[11] Diabaté, A., Zerbo, J.-L. and Ouattara, F. (2019) Variation of the foF2 Parameter during Fluctuating Activity: Prediction with IRI-2012 Compared to Measured Data from Ouagadougou Ionosonde Station during Solar Cycles 21 and 22. Vietnam Journal of Earth Sciences, 41, 69-78. https://doi.org/10.15625/0866-7187/41/1/13549

[12] Faynot, J.M. and Villa, P. (1979) F-Region at the Magnetic Equator. Annales Geophysicae, 35, 1-9.

[13] M'Bi, K., Louis, Z., Christian, Z. and Frédéric, O. (2019) Variability of the Critical Frequency foF2 for Equatorial Regions during Solar Cycle's Minima and Maxima at Ouagadougou and Manila Stations. International Journal of Geosciences, 10, 833-844. https://doi.org/10.4236/ijg.2019.1010047

[14] Dibs, H., Mansor, S., Ahmadb, N. and Al-Ansari, N. (2020) Simulate New Near Equatorial Satellite System by a Novel Multi-Fields and Purposes Remote Sensing Goniometer. Engineering, 12, 325-346. https://doi.org/10.4236/eng.2020.126026

[15] Legrand, J.P. and Simon, P.A. (1989) Solar Cycle and Geomagnetic Activity: A Review for Geophysicists, Part I. The Contributions to Geomagnetic Activity of Shock Waves and of the Solar Wind. Annales Geophysicae, 7, 565-578.

[16] Zerbo, J.L., Amory-Mazaudier, C., Ouattara, F. and Legrand, J.P. and Richardson, J.D. (2012) Solar Wind and Geomagnetism, toward a Standard Classification 1868-2009. Annales Geophysicae, 30, 421-426. https://doi.org/10.5194/angeo-30-421-2012

[17] Clette, F., Svalgaard, L., Vaquero, J.M. and Cliver, E.W. (2014) Revisiting the Sunspot Number. A 400-Year Perspective on the Solar Cycle. Space Science Reviews, 186, 35-103. https://doi.org/10.1007/s11214-014-0074-2

[18] Zerbo, J.L., Ouattara, F., Zoundi, C. and Gyébré, A. (2011) Solar Cycle 21 and Geomagnetic Activity since 1868. Revue CAMES Serie A, 12, 255-262.

[19] Ouattara, F. (2013) IRI-2007 foF2 Predictions at Ouagadougou Station during Quiet Time Periods from 1985 to 1995. Archives of Physics Research, 4, 12-18. https://doi.org/10.9734/PSIJ/2014/9748

[20] Aarons, J. (1993) The Longitudinal Morphology of Equatorial f-Layer Irregularities Relevant to Their Occurrence. Center for Space Physics, Boston University, Boston. 